\title{
Pearls for Secondary Intraocular Lens Implantation
}

\author{
An Expert Interview with Marjan Farid
}

Gavin Herbert Eye Institute, University of California, Irvine, California, US

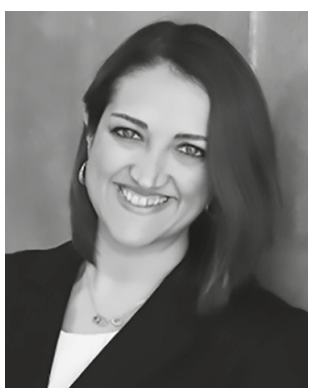

\begin{abstract}
Marjan Farid
Marjan Farid is Director of the Cornea, Cataract, and Refractive Surgery Faculty and Vice-chair of the Ophthalmic Faculty at the Gavin Herbert Eye Institute (GHEI) at the University of California, IIvine (UCI), California, US. Dr Farid's clinical practice is divided between patient care, teaching, and research. She enjoys teaching ophthalmology to medical students, ophthalmology residents, and cornea fellows. She serves on the Residency Education Committee and is the Director of the cornea fellowship program at the GHEI. Her research interests focus on corneal surgery, specifically in the use of the femtosecond laser for corneal transplantation. She performs all forms of corneal transplantation-femtosecond enabled and lamellar keratoplasty (DSEK and DALK). Dr Farid is also the founder of the severe ocular surface disease center at UCl. She performs limbal stem cell transplants, as well as artificial corneal transplantation for the treatment of patients with severe ocular surface disorders. She serves as an associate medical director for the sight Life Eye Bank. Her work has been published in numerous peer-reviewed journals, she has authored six textbook chapters, and travels to multiple national meetings to present her research work. She serves as an Editorial Board member of Ophthalmology, the leading journal in her field. Dr Farid graduated summa cum laude from UCLA with a degree in biology. She earned her medical degree at UC-San Diego in 2002 and completed a transitional year internship at Scripps-Mercy Hospital in San Diego. She completed her residency training in ophthalmology at UCl. She subsequently completed her fellowship training in the area of cornea/external disease and refractive surgery under the mentorship of Dr Roger steinert at UCl.
\end{abstract}

\section{Keywords}

Secondary intraocular lens implantation, intrascleral fixation, posterior

chamber, anterior chamber

Disclosure: Marjan Farid has no conflicts of interest to declare. No funding was received in the publication of this article. This is an expert interview and as such has not undergone the journal's standard peer review process.

Acknowledgements: Editorial assistance was provided by Katrina Mountfort, Freelance Medical Writer, supported by Touch Medical Media.

Authorship: All named authors meet the International Committee of Medical Journal Editors (ICMJE) criteria for authorship of this manuscript, take responsibility for the integrity of the work as a whole, and have given final approval to the version to be published.

open Access: This article is published under the Creative Commons Attribution Noncommercial License, which permits any noncommercial use, distribution, adaptation, and reproduction provided the original author(s) and source are given appropriate credit.

Received: February 6, 2017

Published Online: February 23, 2017

Citation: US Ophthalmic Review, 2017:10(1):13-4

Corresponding Author: Marjan Farid, MD, University of California-Irvine, Gavin Herbert Eye Institute, 850 Health Sciences Road, Irvine, CA 9269, US. E: mfarid@uci.edu
The role of secondary intraocular lens (IOL) implantation has evolved. Following advances in cataract surgery, surgical aphakia is becoming uncommon, and secondary IOL implantation is now most commonly performed as part of an IOL exchange procedure. A number of techniques and IOLs are available for secondary IOL implantation, and debate persists regarding which methods are best for eyes lacking sufficient capsular support. It is therefore important to consider specific techniques, choice of IOL, sutures, and medication regimens, in order to tailor the approach to the individual patient. In an expert interview, Marjan Farid of Gavin Herbert Eye Institute discusses the optimal use of some of the most widely used techniques.

\section{Q: What are the advantages and disadvantages of iris fixation suture lens implantation in aphakic eyes?}

The main advantages to iris-fixated IOLs as a secondary lens option are that they can be performed through a small cataract-sized clear corneal incision and do not require conjunctival or scleral surgery. Standard foldable three-piece IOLs are the preferred lens option in these cases as one-piece acrylic IOLs cannot be used for iris fixation, since they can cause iris chafing. This technique does, however, require normal iris anatomy. The disadvantages to this technique are the potential for pupil ovaling if the sutures are not placed peripheral enough. Furthermore, since manipulation of the iris is required, the risk of uveal irritation and cystoid macular edema (CME) are present.

\section{Q: What surgical techniques can minimize complications in the implantation of iris fixation suture lenses?}

In order to perform iris-fixated IOLs, certain instrumentation is required and will greatly improve the chances of success. A set of hooks to manipulate the IOL and iris (such as Lester or Kuglen hooks), small incision forceps and scissors, and a heavy molecular weight viscoelastic are essential. A combined cohesive and dispersive ophthalmic viscoelastic device (OVD) is my preferred viscoelastic for these cases as it provides excellent endothelial protection, pushes the 
iris down and drapes it over the haptic well, and is easy to wash out at the end of the case. A 10-0 prolene suture on a long curved CTC needle is used to hook and capture the iris/haptic as peripheral as possible to minimize pupil ovaling, and a siepser knot technique will create a tight fixation of the iris to the haptic.

\section{Q: In what situations should intrascleral fixation of posterior chamber IOL be considered?}

In cases where there is poor iris anatomy or absolutely no capsular remnants to support the IOL during the manipulation required for iris fixation, I will choose to perform a scleral fixated secondary IOL technique. In most cases, a trans-scleral tunnel glue-fixated posterior chamber IOL will be the preferred method as this method too can be performed through a small clear corneal incision.

\section{Q: When should an anterior chamber lens be considered?}

In cases where the patient's age is high and there is absolutely no evidence of corneal compromise or decline, a well-fitted anterior chamber IOL can provide excellent outcomes. $\square$ 